Available online at GSC Online Press Directory

GSC Biological and Pharmaceutical Sciences

e-ISSN: 2581-3250, CODEN (USA): GBPSC2

GSC

ONLINE PRESS

Journal homepage: https://www.gsconlinepress.com/journals/gscbps

(RESEARCH ARTICLE)

\title{
Pharmacological potentials of Propolis in urban landscapes
}

\author{
Puspha TC ${ }^{1, *}$ and Reddy MS ${ }^{2}$ \\ ${ }^{1}$ Department of Zoology, Maharanis Science College for Women, Palace Road, Bangalore-560001 India. \\ ${ }^{2}$ Department of Zoology, Bangalore University, Jnana Bharathi, Bangalore-560056, India.
}

Publication history: Received on 25 June 2019; revised on 14 July 2019; accepted on 16 July 2019

Article DOI: https://doi.org/10.30574/gscbps.2019.8.1.0116

\begin{abstract}
Propolis is a resinous material produced by bees from the selective collection of plant exudates that are subsequently mixed with bee's wax and salivary bee secretions. Propolis has been used in folk medicine, and certainly, several studies have validated its biological properties. The chemical composition and pharmacological activities of Propolis collected around urban land scape of Bangalore and have been studied in 2018-2019. There are remarkable differences in the biological activities of Propolis from dissimilar geographical origin, and those mainly depend on the qualitative and quantitative variations of its characteristic chemical constituents, which are provided by botanical sources. Herein, we investigated pharmacological potentials Propolis in urban landscapes.
\end{abstract}

Keywords: Propolis; Pollination; Urban landscape

\section{Introduction}

Bees are the most ecologically important pollinators for flowering plants, a coevolutive activity they have been performing for more than 100 million of years. In particular, eusocial bees have reached an evolutionary success by living in perennial colonies (approximately 50,000 individuals) and developing sophisticated recruitment communication mechanisms to foraging and profit the chemistry of plants via manufacture and application beehive products for their own benefit. According to their significant role as vectors of pollen in agricultural crops and the impact of beehive products for human societies, bees have earned an important position in different civilizations through history and geographies [1, 2]. Indeed, the bee management practice has been described since ancient times, including two types of beekeeping: apiculture (Apinae) and meliponiculture (Meliponinae). The first includes the Asian honeybees (Apis cerana) and western European honeybees (Apis mellifera), while the second refers to the native tropical and subtropical stingless bees (Melipona sp., Oxytrigona sp., Scaptotrigona sp., Tetragonisca sp. and Trigona sp., among others). At present, the beekeeping practice with western European honeybee is geographically widespread as a consequence of human migrations; thus, A. mellifera have settled down in all the lands that men have done, reaching a wide phytogeographical distribution range, including almost every vegetated place on earth. Thus, the chemical diversity of Propolis is dictated by the phytogeographical conditions and the climatic characteristics, and finally by the honeybee species involved in its production [3]. In that sense, the chemical composition of Propolis from dense forest ecosystem (Western Ghats) differs from those of Urban land scape of Bangalore Propolis, a complex mixture of compounds also called bee glue, is a natural resinous product that honeybees collect from several plants and mix it with beeswax and salivary enzymes ( $\beta$-glucosidase). Since ancient times, Propolis has been used by humans to meet the needs of health and food preservation but only in the last years the interest in this complex natural product has increased due to its broad spectrum of biological and pharmacological properties [4]. Analysis of different samples revealed that Propolis chemical composition is difficult to standardize because it depends on different phytogeographic characteristics like vegetation, season, and environmental conditions of the site of collection, as bees select different plants in different habitats for Propolis production. Several in-vitro and in-

\footnotetext{
${ }^{*}$ Corresponding author

E-mail address: pusphatc@gmail.com
} 
vivo studies have been describing the plethora of biological activities and chemical profiles of Propolis from different geographic origins. The insights of chemical constitute of Propolis would render bee biodiversity and their genetic constitution.

\section{Material and methods}

\subsection{Collection and sample preparation}

The Propolis samples were obtained directly from individual beekeepers from the Apiary centers situated on different locations in Bangalore. A total of 80 Propolis samples belonging to Apis mellifera, Apis cerana and Stingless bee Tetragonula irridipenis colonies were collected from bee hives of six different location of Bangalore during the early summer season (2017-2018). The Propolis sample were packed into plastic bags and stored in a refrigerator at $4^{\circ} \mathrm{C}$, until further processing in bottles protected with laminated paper in inert atmospheric conditions in order to avoid degradation of the material. Propolis samples (from Apis mellifera, Apis cerana and Stingless Bee Tetragonula irridipenis were prepared by weighing approximately fifty (50) grams, washed with water to remove incorporated dirt and sugars. The washings were tested with Benedict's solution for the presence of glucose and fructose. It was ensured that none of the sugars was detected in each sample before extraction with organic solvents. Washed samples was placed in a glass jar and frozen at $-10^{\circ} \mathrm{C}$. after that Propolis was grinded and mixed with $70 \%$ ethanol with the ratio of 1: 20. The solution was shaken for 10 days in the dark, then it was filtered and the filter cake was mixed with $70 \%$ ethanol again for additional two days. The solution was filtered and it was kept overnight in the refrigerator for wax removal. Then the solution was filtered again through Whatman filter No.1 and let evaporated for removal of the solvent. The filtrate lyophilized for 48 hours the Extract used for measuring physical characteristics and pharmacological potentials.

\subsection{Total polyphenol contents}

Total polyphenol contents were determined according to the Folin-Ciocalteu colorimetric method, using p-coumaric acid as reference. The analyses were carried out in triplicates of each sample.

\subsection{Total flavonoid contents}

Total flavonoid contents were determined by the aluminium chloride and dinitrophenylhydrazine methods. Calibration curves were made using quercetin (aluminium chloride method) and pinocembrin (dinitrophenylhydrazin method) as reference. Total flavonoid contents were assumed to be the sum of the values obtained by each method. Analyses were performed in triplicates.

\subsection{Antioxidant activity of Propolis}

The radical scavenging effect on 2,2-diphenyl-1-picrylhydrazyl (DPPH) molecules was evaluated Samples were dissolved in a buffer solution at a final concentration of $1 \mu \mathrm{g} / \mathrm{mL}$ or final dilution of $1 \mu \mathrm{L} / \mathrm{mL}$. For each extract, a series of test tubes were prepared containing between 1 and $1000 \mu \mathrm{L}$ of these solutions, and the volume completed to 1000 $\mu \mathrm{L}$ with buffer. Finally, $1 \mathrm{~mL}$ of a $500 \mu \mathrm{M}$ DPPH solution was added to each tube. After 30 min of incubation at room temperature in the dark, the absorbance was recorded at $517 \mathrm{~nm}$ by a spectrophotometer. Results are expressed in terms of the percentage of decrease with respect to control values (absorbance of $1 \mathrm{~mL}$ DPPH solution $+1 \mathrm{~mL}$ of buffer) incubated under the same conditions. Readings were made in triplicate. The mean of each result is plotted on a graph constructed by plotting increasing concentrations of the antioxidant trolox (6-hydroxy-2,5,7,8tetramethylchroman-2-carboxylic acid) vs. Optical Density (OD) values. Propolis samples' antioxidant activity is expressed as $\mu$ g trolox equivalent.

\section{Results and discussions}

Results of physical properties of Propolis showed wide differences especially in color between different samples depending on geographical origin and flora vegetation in that area. Table (1) summarizes the important physical properties from different localities: colors of different sample had a broad range of varieties, it ranges between brownish yellow to dark brown in Apis mellifera Propolis (moderate vegetation) sample depending on flora vegetation that was mixed with different plants, and according to geographical position, as mentioned $[5,6]$. 
Table 1 Physical properties of Propolis

\begin{tabular}{|c|c|c|c|c|c|}
\hline Sample & Species & Location & Color & Texture & Odor \\
\hline 1 & Apis mellifera & $\mathrm{L}-1$ & Brown & waxy & Aromatic \\
\hline 2 & Apis mellifera & $\mathrm{L}-2$ & Dark brown & waxy & Aromatic \\
\hline 3 & Apis mellifera & $\mathrm{L}-3$ & Black & waxy & Aromatic \\
\hline 4 & Apis mellifera & $\mathrm{L}-4$ & Dark brown & waxy & Aromatic \\
\hline 5 & Apis melliferaq & $\mathrm{L}-5$ & Brown & waxy & Aromatic \\
\hline 6 & Apis mellifera & L-6 & Brown & waxy & Aromatic \\
\hline 7 & Apis Cerana & $\mathrm{L}-1$ & Light brown & Thin flakes & Slightly Aromatic \\
\hline 8 & ApisCerana & $\mathrm{L}-2$ & Brown & solid flakes & Slightly Aromatic \\
\hline 9 & Apis Cerana & $\mathrm{L}-3$ & Brown & Flakes & Slightly Aromatic \\
\hline 10 & Apis Cerana & $\mathrm{L}-4$ & Light brown & Thin flakes & Slightly Aromatic \\
\hline 11 & Apis Cerana & $L-5$ & Light brown & Thin flakes & Slightly Aromatic \\
\hline 12 & Apis Cerana & L-6 & Light brown & Thin flakes & Slightly Aromatic \\
\hline 13 & Stingless bee & $\mathrm{L}-1$ & Yellowish brown & Solid & Aromatic \\
\hline 14 & Stingless bee & $\mathrm{L}-2$ & Brown & Solid & Aromatic \\
\hline 15 & Stingless bee & $\mathrm{L}-3$ & Yellowish brown & Solid & Aromatic \\
\hline 16 & Stingless bee & $\mathrm{L}-4$ & Golden brown & Solid & Aromatic \\
\hline 17 & Stingless bee & $\mathrm{L}-5$ & Brown & Solid & Aromatic \\
\hline 18 & Stingless bee & L-6 & Yellowish brown & Solid & Aromatic \\
\hline
\end{tabular}

Table 2 Total polyphenols, flavonoids, tannins, protein, ascorbic acid, and reducing sugar contents

\begin{tabular}{|c|c|c|c|}
\hline Phytochemicals & $\begin{array}{l}\text { Amount } \\
\text { landscape }\end{array}$ & Urban & Amount (mg/g) Coorg region \\
\hline Total polyphenols (GAEs) & $15.93 \pm 0.18$ & & $19.21 \pm 0.16$ \\
\hline Total flavonoids (CEs) & $1.65 \pm 0.10$ & & $4.65 \pm 0.17$ \\
\hline Total tannins (TEs) & $5.81 \pm 1.65$ & & $3.81 \pm 0.18$ \\
\hline Total protein (BSA) & $24.54 \pm 0.26$ & & $28.13 \pm 0.07$ \\
\hline Reducing sugar (D-glucose) & $38.22 \pm 3.22$ & & $46.00 \pm 1.22$ \\
\hline
\end{tabular}

Flavonoids and polyphenolic compounds form about 45-50\% of Propolis composition in general and exhibit important role in Propolis color (Table-2). Whereas Silva and co-workers reported chemical composition and botanical origin of Propolis, which depends on secretions of plant species that were often mentioned as its probable botanical source. Texture of Apismellifera Propolis was rigid and soft, and in general, Propolis contains about $30 \%$ of wax, which affects the texture. Concerning L5 Propolis odor, most of the samples were aromatic resinous depends on flora vegetation, and types of chemical compounds were essential and aromatic oils, which form 10\% of Propolis composition, Apismellifera Propolis odor was very aromatic resinous, while coorg region Tetragonidia irridipenis (richvegetation) it was mildly aromatic, other samples from other regions were aromatic resinous. Antioxidant activity The DPPH radical scavenging activity using commercial Propolis extracts are shown in Table 3. 
Table 3 Antioxidant activity of propolis and $\alpha$-Tocopherol via DPPH

\begin{tabular}{llccc}
\hline \multirow{2}{*}{$\begin{array}{l}\text { Commercial } \\
\text { sample }\end{array}$} & \multicolumn{2}{c}{ Antioxidant Activity } & \multicolumn{2}{c}{ Maximum RSA \% } \\
\cline { 2 - 5 } & \multicolumn{2}{c}{ IC50 $\mathbf{~ m g} / \mathbf{~ m L} \pm$ SD } & \multicolumn{2}{c}{ RSA \% \pm SD } \\
\cline { 2 - 5 } & Urban landscape & Coorg region & Urban landscape & Coorg region \\
\hline $\begin{array}{l}\text { Propolis Extract } \\
\begin{array}{l}\text { Average) } \\
\alpha \text {-tocopherol }\end{array}\end{array}$ & $6.101 \pm 0.014$ & $4.101 \pm 0.1$ & $97.0 \pm 0.1$ & $96.0 \pm 0.1$ \\
\hline
\end{tabular}

Phenolic compounds present in Propolis extracts showed activity effective in sequestering the DPPH radical, with similar percentages around 97\%. There is no significance difference among Propolis extract using Anova one-way Tukey's test with $\mathrm{p}$ value $<0.05$. The antioxidant activity showed values similar to those found by $[7,8]$. The researcher studied the antioxidant capacity of Propolis from different regions of the Brazil and average values of $88 \%$ for the Southeast, $89 \%$ for Propolis of Rio de Janeiro and $75.7 \%$ for the Northeast Propolis. Some papers correlate a probable existence of phenolic compounds present in the ethanolic solution, with the positive action of antioxidant activity $[9,10]$. Antioxidant activity of Propolis is attributed to flavonoid components, among which we can mention quercetin, daidzein, genistein and apigenin. Quercetin and daidzein were detected in the Brazilian red Propolis of Alagoas. Other studies have also detected the antioxidant activity of the flavonoid isoliquiritigenin and kaempferol and CAPE (phenethyl caffeate in Propolis samples [11, 12,13]. A high percentage of antioxidant activity demonstrated by free radical sequestration method DPPH and high percentage concentration of total phenolics and total flavonoids corroborate the qualitative results of phytochemical screening that detected the presence of several phenolic compounds during the course of this phytochemical test. Our results have a broad spatial and temporal scope that facilitates generalizations about honey bees pollinating urban garden and likely in other similar intensively dense agro-environments [14]. However, we did not anticipate significant differences among the other site types in floral diversity; these differences suggest that either management practices in those crops differentially affect diversity or that the original abiotic and biotic conditions did so while simultaneously favoring sowing of specific crops. It is also possible that seasonal timing of these sites had an effect, with earlier sites tending to have less diversity than later sites in the summer.

\section{Conclusion}

Climate variations might induce changes in the concentration of bioactive compounds of plants, with consequent alterations in the biological activity of the various types of Propolis. Although, therapeutic standardization of Propolis is challenging, and the relationship between definite types of Propolis and specific biological activities is difficult to establish, the presence of a significant amount of one specific compound might lead to the expectance that the extract has the potential to show bioactivities linked to this potential. The chemical composition of Uraban land scape Propolis is quite different from that of Propolis from Coorg region as a function of the tropical climate, plant diversity and bee species, the latter resulting from the crossing of other species.

\section{Compliance with ethical standards}

\section{Acknowledgments}

Authors expressing sincere thanks to Bangalore University and Maharani Cluster University

\section{Disclosure of conflict of interest}

Pushpa conducted experiments, M.S Reddy is written the manuscript.

\section{References}

[1] Toreti VC, Sato HH, Pastore GM and Park YK. (2013). Recent progress of Propolis for its biological and chemical compositions and its botanical origin. Evidence-based complementary and alternative medicine. 
[2] Sforcin JM, Bankova V. (2011). Propolis: is there a potential for the development of new drugs? J Ethnopharmacol, 133, 253-60.

[3] Bankova V. (2005). Chemical diversity of Propolis and the problem of standardization. J Ethnopharmacol, 100, 114-117.

[4] Bankova V. (2005). Recent trends and important developments in Propolis research. Evid Based Complement Alternat Med. 2, 29-32.

[5] Trusheva B, Popova M, Bankova V, Simova S, Marcucci MC, Miorin PL, et al. (2006). Bioactive constituents of Brazilian red Propolis. Evid Based Complement Alternat Med. 3, 249-254.

[6] Frozza COS, Garcia CSC, Gambato G, Souza MDO, Salvador M, Moura S, et al. (2013). Chemical characterization, antioxidant and cytotoxic activities of Brazilian red Propolis. Food Chem Toxicol. 52, 137-142.

[7] Okoh SO, Asekun OT, Familoni OB and Afolayan AJ. (2014). Antioxidant and free radical scavenging capacity of seed and shell essential oils extracted from Abrus precatorius (L) Antioxidants. 3, 278-287.

[8] Cabral ISR, Oldoni TLC and Prado A. (2009). Phenolic composition and antibacterial and antioxidant activity of Brazilian red Propolis. Quim Nova. 32, 1523-1527.

[9] Zhang X, Yeung ED, Wang J, Panzhinskiy EE, Tong C, Li W and Li J. (2010). Isoliquiritigenin, a natural antioxidant, selectively inhibits the proliferation of prostate cancer cells. Clin Exp Pharmacol Physiol, 37, 841-847.

[10] Ondrias K, Stasko A, Hromadová M, Suchy V and Nagy M. (1997). Pinobanksin inhibits peroxidation of lowdensity lipoprotein and it has electron donor properties reducing alpha-tocopherol radicals. DiePharmazie, 52, 566-567.

[11] Blanco-Ayala T, Lugo-Huitrón R, Serrano-Lopez EM, Reyes-Chilpa R, Rangel-López E, Pineda B, et al. (2013). Antioxidant properties of xanthones from Calophyllum brasiliense: prevention of oxidative damage induced by FeSO. BMC Complement Altern Med. 11, 213-217.

[12] Kiełbus M, Skalicka-Woźniak K, Grabarska A, Jeleniewicz W, Dmoszyńska-Graniczka M, Marston A, Polberg K, Gawda P, Klatka J and Stepulak A. (2013). 7-Substituted Coumarins Inhibit Proliferation and Migration of Laryngeal Cancer Cells In Vitro. Anticancer Res. 33, 4347-4356.

[13] Rashed KN and Butnariu M. (2014). Isolation and antimicrobial and antioxidant evaluation of bioactive compounds from Eriobotrya japonica stems. Adv Pharm Bull, 4, 75-81.

\section{How to cite this article}

Puspha TC and Reddy MS. (2019). Pharmacological potentials Propolis in urban landscapes. GSC Biological and Pharmaceutical Sciences, 8(1), 134-138. 